\title{
PHYTOCHEMICAL SCREENING, CONTRIBUTION TO THE STUDY OF THE ANTIFUNGAL EFFECT OF FLAVONOIDS FROM DIFFERENT PARTS OF ZIZIPHUS LOTUS OF SOUTH-WEST ALGERIA
}

\author{
SLIMANI ALAA ${ }^{1 *}$, MOUSSAOUI ABDELLAH ${ }^{1}$, LAAZOUNI HAMADI ${ }^{2}$ \\ ${ }^{1}$ Laboratory of Plant Resource Development and Food Security in Semi Arid Areas, Department of Biology, University of Bechar, South \\ West of Algeria, BP 417, Algeria. ${ }^{2}$ Department of Biology, Natural Product Laboratory, University Abou Bakr Belkaid, BP 119, Imama \\ Tlemcen, Algeria. Email: slimani.alaa@yahoo.fr \\ Received: 09 August 2016, Revised and Accepted: 22 November 2016
}

\section{ABSTRACT}

The biodiversity of our country allows us to medicinal plants used in the new research directions most of the plants used in traditional medicine for centuries. Because of the resistance of the proliferation of parasitic fungi in the food industries, plant diseases, this work aims to test the antifungal activity of a plant heritage which is the Ziziphus lotus. The phytochemical screening allowed us to see that the flavonoids extracts of leaves, roots, and seeds covered in this study are rich in bioactive substances namely alkaloids, flavonoids, saponins, tannins, and terpenes. Antifungal activity was tested using two methods; radial growth on solid media and evaluation of biomass on liquid environments against Aspergillus flavus-parasiticus and Aspergillus ochraceus. The results of the evaluation of the radial growth show that the extract of flavonoids of the best roots given percent inhibition of $73.3 \%$ against $A$. ochraceus has $4.37 \times 10^{-4} \mathrm{~g} / \mathrm{ml}$ concentration, followed by extraction of flavonoids grains that gave an inhibition of $55 \%$ against the Aspergillus flavus-parasiticus has $1.091 \times 10^{-3} \mathrm{~g} / \mathrm{ml}$ concentration. However, another extract of $Z$. lotus gave a fairly significant inhibition of fungal strains studied very limited. The results of the evaluation of biomass on liquid medium show the efficacy vis-à-vis studied extracts of the strains tested in accordance with the increase of the concentration thereof. The best inhibition was recorded for extraction of flavonoids grain against the two strains tested $61.92 \%$ for Aspergillus flavus-parasiticus and $84.33 \%$ for A. ochraceus $1.091 \times 10^{-3} \mathrm{~g} / \mathrm{ml}$ concentration.

Keywords: Ziziphus lotus, Extracts flavonoids, Antifungal activity, Aspergillus flavus-parasiticus, Aspergillus ochraceus.

(c) 2017 The Authors. Published by Innovare Academic Sciences Pvt Ltd. This is an open access article under the CC BY license (http://creativecommons. org/licenses/by/4. 0/) DOI: http://dx.doi.org/10.22159/ajpcr.2017.v10i2.14595

\section{INTRODUCTION}

A large number of plants (aromatic, medicinal, spice, and other plants) have interesting biological properties which they find applications in various areas, namely in medicine, pharmacy, and cosmetology. However, evaluation of antioxidant and antimicrobial properties of plant protection continues to be a very interesting task useful particles for plants of rare or less common or not known use in traditional medicine [1].

These plants represent a new source of active compounds, in fact, the secondary metabolites are the subject of numerous research in vivo and in vitro including the search for new natural component such as phenolics, saponins, essential oils, and extracts.

Ziziphus lotus is a shrub widely used in the treatment of certain diseases such as digestive disorders, weakness, liver ailments, The obesity il also has antimicrobial activity (antifungal, antibacterial, and antioxidant).

The aim of this work is the problem of reducing fungal flora producing of mycotoxins by focusing on the study of the antifungal activity of flavonoids extracts from different parts of $Z$. lotus (seeds, leaves, and roots) on toxigenic molds Aspergillus flavus-parasiticus and Aspergillus ochraceus producing of aflatoxin and ochratoxin A.

\section{EXPERIMENTAL SECTION}

Plant material

The harvesting of the plant to study Z. lotus was conducted in the month of December 2014-February 2015 from Lahmar in the region of Bechar located at $1150 \mathrm{~km}$ southwest of the capital, Algiers. The harvested leaves, seeds, and roots have been cleaned and free of debris, then spread on in thin layers, returned frequently, paper drying operated out in the open and protected from light at room temperature for 15 days.
The dried leaves were crushed and preserved in glass jars tightly closed until their uses.

\section{Qualitative phytochemical screening}

Studies of plants are requiring knowledge of biological activities and/or chemical constituents. Indeed, this knowledge can be used for the discovery of therapeutic agents.

One of the essential purposes of the phytochemical screening is the detection of classes of compounds existing in the different plant organs (root, stem, leaf, epicarp, pulp, and seed). This is the first step in finding molecules with therapeutic activities [2].

\section{Preparation of plant extract}

Aqueous maceration

Aqueous maceration is performed on $10 \mathrm{~g}$ of the sample (leaves, seeds and roots dried, and crushed) with $100 \mathrm{ml}$ of distilled water and placed under shaking for $24 \mathrm{~h}$ at room temperature, then aqueous macerate was filtered through filter paper MN 640 of $125 \mathrm{~mm}$ in diameter, to remove fine particles [3]. After filtration, the extract was concentrated in vacuum at $100^{\circ} \mathrm{C}$ by rotary evaporator (Buchi Rotavapor R-215) [4]. Finally, the aqueous macerate is kept in a sterile bottle tightly closed and covered with aluminum foil to prevent any penetration of rays indoors. The conservation was made at $4^{\circ} \mathrm{C}$.

\section{Aqueous extraction}

About $10 \mathrm{~g}$ of crushed leaves, seeds or roots of $Z$. lotus was introduced with $100 \mathrm{ml}$ of distilled water. All was brought to the boil for $1 \mathrm{~h}$ under reflux [3]. The extracts were filtered through filter paper MN 640 of $125 \mathrm{~mm}$ in diameter, to remove fine particles [3] and concentrated in vacuum at $100^{\circ} \mathrm{C}$ to the rotavapor to eliminate the residual fraction of solvent. The conservation was made at $4^{\circ} \mathrm{C}$. 


\section{Ethanol maceration}

About $10 \mathrm{~g}$ of the sample (dried and crushed leaves, seeds or roots) is mixed with $100 \mathrm{ml}$ of $50 \%$ ethanol and placed under shaking for $24 \mathrm{~h}$ at room temperature. After filtration with filter paper MN 640 of $125 \mathrm{~mm}$ in diameter, to remove fine particles, the extract was concentrated in vacuum at $100^{\circ} \mathrm{C}$ by rotary evaporator (Buchi Rotavapor R-215) [5]. The obtained macerates were collected in sterile flasks and stored at $4{ }^{\circ} \mathrm{C}$

\section{Ethanol extraction}

About $10 \mathrm{~g}$ of crushed leaves, grains or roots of $Z$. lotus was introduced with $100 \mathrm{ml}$ of $50 \%$ ethanol. All was brought to the boil for $1 \mathrm{~h}$ under reflux [3]. The extracts were filtered through filter paper MN 640 of $125 \mathrm{~mm}$ in diameter, to remove fine particles, and concentrated in vacuum at $100^{\circ} \mathrm{C}$ by rotary evaporator (Buchi Rotavapor R-215) to eliminate the residual fraction of solvent [6]. The conservation was made at $4^{\circ} \mathrm{C}$

\section{Extraction of flavonoids}

About 50 g powder of $Z$. lotus (seeds, roots, and leaves) were heated separately to $900^{\circ} \mathrm{C}$ under reflux in a mixture (distilled/ethanol water) ( $250 \mathrm{ml} / 250 \mathrm{ml}$ ) for $4 \mathrm{hrs}$. Followed by filtration through a Watman filter paper of porosity $0.45 \mu \mathrm{m}$ was performed.

The aqueous-ethanolic phase was evaporated to remove ethanol and follows extracted with $100 \mathrm{ml}$ of n-butanol, and then, acidified with $10 \% \mathrm{HCl}$ to $\mathrm{pH}=3$, n-butanol phase was evaporated to dryness.

The dry residue was extracted three times with $200 \mathrm{ml}$ of distilled water/ethyl acetate (v/v) for $1 \mathrm{hr}$, the organic phase was basified with $\mathrm{NaHCO}_{3}$ until pH = 9, after 15 minutes of rest, the organic phase (flavonoids) was evaporated to dryness, weighed and taken over by the $1 \%$ ethanol for biological test.

\section{Origin of fungal strains}

Aspergillus flavus-parasiticus and A. ochraceus are fungal strains used in this work was provided by biology research laboratory (laboratory upgrading of plant resources and food safety in semiarid areas) University Tahri Mohamed Bechar. The choice of strains was based on their degree of toxicity by contaminating food and ability to synthesize certain toxic secondary metabolites: Mycotoxins. Species of Aspergillus flavus-parasiticus and A. ochraceus are identified by the "Single Spore" method described by Pitt [7]. A pure culture of 7 days recovered species are inoculated using a Platinum loop in hemolyzed tubes filled with a solid semi-solution of $0.2 \%$ Agar and a few drops of tween 80 . The whole is then stirred with a vortex for homogenization.

\section{Antifungal activity}

The antifungal activity of extracts of flavonoids (leaves, seeds, and roots) was performed by two methods: The method of evaluation of the radial growth on solid medium potatoes dextrose agar (PDA) and the method of evaluation of the fungal biomass to liquid media (broadcast on liquid medium).

\section{Evaluation of radial growth on solid media}

The antifungal activity of flavonoids from different parts of Z. lotus plant was tested by the method used [8] where each plant extract of Z. lotus: Seeds, roots, and leaves, is tested by the addition of different concentrations of $\left(1.794 \times 10^{-3} \mathrm{~g} / \mathrm{ml}, 2.691 \times 10^{-3} \mathrm{~g} / \mathrm{ml}, 3.588 \times 10^{-3} \mathrm{~g} / \mathrm{ml}\right.$, $\left.4.485 \times 10^{-3} \mathrm{~g} / \mathrm{ml}\right)$ leaves, $\left(1.748 \times 10^{-4} \mathrm{~g} / \mathrm{ml}, 2.622 \times 10^{-4 \mathrm{~g}} / \mathrm{ml}, 3.496 \times 10^{-4 \mathrm{~g}} / \mathrm{ml}\right.$, $\left.4.37 \times 10^{-4} \mathrm{~g} / \mathrm{ml}\right)$ of roots, and $\left(4.364 \times 10^{-4} \mathrm{~g} / \mathrm{ml}, 6.546 \times 10^{-4} \mathrm{~g} / \mathrm{ml}\right.$, $8.728 \times 10^{-4} \mathrm{~g} / \mathrm{ml}, 1.091 \times 10^{-3} \mathrm{~g} / \mathrm{ml}$ ) the grains of the extract to a volume of PDA medium supplemented with $20 \mathrm{ml}$. After shaking the tubes by vortexing, the mixture is poured into Petri dishes [9].

\section{Assessment of biomass on medium liquid}

In vials containing $60 \mathrm{ml}$ of potato dextrose broth (PDB) medium was added at various concentrations extracts the leaves $\left(1.794 \times 10^{-3} \mathrm{~g} / \mathrm{ml}, 2.691 \times 10^{-3} \mathrm{~g} / \mathrm{ml}, 3.588 \times 10^{-3}, 4.485 \times 10^{-3} \mathrm{~g} / \mathrm{ml}\right)$, roots $\left(1.748 \times 10^{-4} \mathrm{~g} / \mathrm{ml}, 2.622 \times 10^{-4} \mathrm{~g} / \mathrm{ml}, 3.496 \times 10^{-4} \mathrm{~g} / \mathrm{ml}, 4.37 \times 10^{-4} \mathrm{~g} / \mathrm{ml}\right)$, and the seeds $\left(4.364 \times 10^{-4} \mathrm{~g} / \mathrm{ml}, 6.546 \times 10^{-4} \mathrm{~g} / \mathrm{ml}, 8.728 \times 10^{-4} \mathrm{~g} / \mathrm{ml}\right.$,
$1.091 \times 10^{-3} \mathrm{~g} / \mathrm{ml}$ ) then was added a quantity of the spores. A $60 \mathrm{ml}$ bottle of PDB medium was inoculated with fungal spores to represent a witness. After stirring, incubation was made at $25^{\circ} \mathrm{C}$ for 14 days.

\section{RESULTS AND DISCUSSION}

\section{Phytochemical screening}

During this phytochemical study, screening allowed us to characterize the different families of existing chemical compounds in the leaves, seeds, and roots of $Z$. lotus. The results of phytochemical tests performed on extracts from the leaves, seeds, and roots reveal the presence of all the elements analyzed: Flavonoids, alkaloids, saponins, tannins, sterols, and terpenes. The phytochemical screening results are illustrated in Table 1.

The phytochemical screening performed on the leaves, roots, and seeds of $Z$. lotus show the presence of alkaloids, flavonoids, saponins, tannins, and terpenes. These results are in agreement with those of the work of [2] which demonstrated the presence of alkaloids, flavonoids, saponins, tannins, and terpenes in the same genus is Ziziphus mauritiana.

\section{Antifungal activity}

The comparative study of the results obtained it was observed that the effectiveness of the extract of the grain is higher by flavonoids contribution to extracts from flavonoids of leaves and roots that show that the grains possess a higher antifungal activity [10].

\section{Evaluation of radial growth on solid medium}

The technique of radial growth on solid media is a qualitative technique based on the measurement of inhibition in $\mathrm{mm}$ diameters. The results of this methods show that flavonoids extracts from the leaves of $Z$. lotus proved to be active against all strains tested. We note that there is a decrease in radial growth of two strains tested (Aspergillus flavus - parasiticus and A. ochraceus). One notices that there is a decrease of the radial growth of the two strains examined (Aspergillus flavus-parasiticus and $A$. ochraceus) depending on the concentration of the extract flavonoids leaves $Z$. lotus.

The inhibition rate and the diameters of fungal strains indicate that there is an antifungal effect of the extract of flavonoids from plant roots studied against the same fungal strains. The reading of the results allowed us to see a decrease in Aspergillus flavus-parasiticus growth and A. ochraceus compared to the control.

The results of the study of the antifungal activity of the extract of $Z$. lotus seeds of flavonoids against A. flavus-parasiticus and A. ochraceus strains by the method of radial growth on solid medium is clear that there have antifungal effect results in a slight reduction of fungal growth compared to the control. Tables 2-4 show the results of the action of extracts of the leaves, roots, and seeds of $Z$. lotus on strains of genus Aspergillus.

The evaluation of the antifungal activity on solid medium PDAa shows the efficacy of the extract flavonoids $Z$. lotus grains of the plant on the inhibition of the growth of Aspergillus flavus-parasiticus, and for the strain $A$. ochraceus, extract the most effective one extract flavonoids roots of the plant $Z$. lotus.

The biological activities of extracts prepared from plants are sometimes

Table 1: Phytochemical screening of Ziziphus lotus

\begin{tabular}{llll}
\hline Phytoconstituents & Leaves results & Roots results & Seeds results \\
\hline Alkaloids & + & + & + \\
Flavonoids & + & + & + \\
Saponins & ++ & ++ & ++ \\
Tannins & + & + & + \\
Sterols and terpenes & + & + & + \\
\hline
\end{tabular}

$(+)$ refers to presence of element analyzed,++: Powerful presence 
due to their high dry matter especially when they are rich in flavonoids and tannins that are part of the most known for their antibacterial and antifungal effect substances [11].

Flavonoids have antimicrobial activity mainly due to the ability of these molecules to inhibit the expression of the DNA and the synthesis of some enzymes and membrane proteins from microorganisms. Indeed, flavonoids like the majority of polyphenols have a very potent antifungal activity. They further actions for the treatment of inflammation, viral infections, and cancer [12]

\section{Assessment of biomass on liquid medium}

The evaluation of biomass on liquid medium containing different concentrations of extracts of $Z$. lotus flavonoids found that various extracts have an antifungal effect on the two strains tested. The results obtained by this technique are shown in Tables 5-7.

Antifungal activity of different extracts of $Z$. lotus flavonoids was evaluated in liquid medium by measuring the weight of the biomass from the fungal flora.
The results of the antifungal activity on liquid medium PDB are incoordination with those of radial growth in solid media. Indeed, the extracts of the leaves of Acacia raddiana had a reducing effect on the weight of the fungal biomass formed. The analysis of our results we note that all extracts and aqueous and ethanolic leaf macerates induced fungal biomasses of both strains reduced. This can be explained by the rate of growth of $A$. flavus-parasiticus contribution to the A. ochraceus.

The best inhibition is marked by the flavonoids extracted from the grains against the two strains tested Aspergillus flavus-parasiticus and A. ochraceus.

The Z. lotus plant has an antimicrobial effect [13] showed that the test antimicrobial activity of different extract is active, besides all microbial strains tested (bacteria and yeasts) are inhibited by at least one extracts of which the etheric extract that has more activity (a zone of inhibition $>45 \mathrm{~mm}$ ) higher than the antibiotic tested.

\section{CONCLUSION}

Modern science, analyzes, and studies the therapeutic effects of plants to compare and rank the various properties and aggregate plants

Table 2: Antifungal activity of flavonoids extracts concentrations $(\mathrm{g} / \mathrm{ml})$ of the leavesof Zizyphus lotus depending on the diameter of fungal growth $(\mathrm{mm})$

\begin{tabular}{|c|c|c|c|c|c|}
\hline Fungal strains & Witness & $1.794 \times 10^{-3}$ & $2.691 \times 10^{-3}$ & $3.588 \times 10^{-3}$ & $4.485 \times 10^{-3}$ \\
\hline Aspergillus flavus-parasiticus & 50 & 40 & 33 & 31 & 25 \\
\hline Aspergillus ochraceus & 30 & 23 & 20 & 19 & 18 \\
\hline
\end{tabular}

Table 3: Antifungal activity of flavonoids extracts concentrations $(\mathrm{g} / \mathrm{ml})$ of the roots of Zizyphus lotus depending on the diameter of fungal growth (mm)

\begin{tabular}{|c|c|c|c|c|c|}
\hline Fungal strains & Witness & $1.748 \times 10^{-4}$ & $2.622 \times 10^{-4}$ & $3.496 \times 10^{-4}$ & $4.37 \times 10^{-4}$ \\
\hline Aspergillus flavus-parasiticus & 50 & 45 & 43 & 35 & 30 \\
\hline Aspergillus ochraceus & 30 & 9 & 9 & 9 & 8 \\
\hline
\end{tabular}

Table 4: Antifungal activity of flavonoids extracts concentrations $(\mathrm{g} / \mathrm{ml})$ of the seeds of Zizyphus lotus depending on the diameter of fungal growth (mm)

\begin{tabular}{|c|c|c|c|c|c|}
\hline Fungal strains & Witness & $4.364 \times 10^{-4}$ & $6.546 \times 10^{-4}$ & $8.728 \times 10^{-4}$ & $1.091 \times 10^{-3}$ \\
\hline Aspergillus flavus-parasiticus & 50 & 45 & 40 & 35 & 22 \\
\hline Aspergillus ochraceus & 30 & 15 & 12 & 11 & 10 \\
\hline
\end{tabular}

Table 5: Weight formed biomass (Aspergillus flavus parasiticus and Aspergillus ochraceus) in the presence of flavonoids extract concentration $(\mathrm{g} / \mathrm{ml})$ of the leaves of Zizyphus lotus $(\mathrm{g})$

\begin{tabular}{|c|c|c|c|c|c|}
\hline Fungal strains & Witness & $1.794 \times 10^{-3}$ & $2.691 \times 10^{-3}$ & $3.588 \times 10^{-3}$ & $4.485 \times 10^{-3}$ \\
\hline Aspergillusflavus-parasiticus & 3,477 & 2,729 & 2,654 & 2,619 & 2,130 \\
\hline Aspergillusochraceus & 1,475 & 1,100 & 1,066 & 1,013 & 0,414 \\
\hline
\end{tabular}

Table 6: Weight formed biomass (Aspergillus flavus-parasiticus and Aspergillus ochraceus) in the presence of flavonoids extract concentration $(\mathrm{g} / \mathrm{ml})$ of the roots of Zizyphus lotus $(\mathrm{g})$

\begin{tabular}{|c|c|c|c|c|c|}
\hline Fungal strains & Witness & $1.748 \times 10^{-43}$ & $2.622 \times 10^{-4}$ & $3.496 \times 10^{-4}$ & $4.37 \times 10^{-4}$ \\
\hline Aspergillusflavus-parasiticus & 3,477 & 3,018 & 2,586 & 2,285 & 1,379 \\
\hline Aspergillusochraceus & 1,475 & 1,217 & 1,161 & 1,154 & 1,066 \\
\hline
\end{tabular}

Table 7: Weight formed biomass (Aspergillus flavus-parasiticus and Aspergillus ochraceus) in the presence of flavonoids extract concentration $(\mathrm{g} / \mathrm{ml})$ of the seeds of Zizyphus lotus $(\mathrm{g})$

\begin{tabular}{|c|c|c|c|c|c|}
\hline Fungal strains & Witness & $4.364 \times 10^{-4}$ & $6.546 \times 10^{-4}$ & $8.728 \times 10^{-4}$ & $1.091 \times 10^{-3}$ \\
\hline Aspergillusflavus-parasiticus & 3,477 & 2,768 & 2,457 & 1,831 & 1,324 \\
\hline Aspergillusochraceus & 1,475 & 1,085 & 0,662 & 0,62 & 0,231 \\
\hline
\end{tabular}


similar effects, then choose their efficiency and make them known. The plants are capable of producing a wide variety of products that do not participate in their basic metabolism but rather representative of the products of secondary metabolism have low toxicity and many biological benefits. To discover the benefits of these herbs have been studying the chemical composition and antifungal activity of $Z$. lotus. The results obtained during the screening phytochemical show that the leaves, roots, and the Z. lotus seeds are rich in phytoconstituents, namely alkaloids, flavonoids, saponins, tannins, and terpenes. In the second part of our study concerning the evaluation of the antifungal effect of flavonoids extracted from different parts of $Z$. lotus, the results show that flavonoids extracted from the grains haves an antifungal effect more active. Moreover, all the extracts induced a significant activity vis-à-vis the strains tested.

\section{ACKNOWLEDGMENTS}

The authors are highly thankful to head, Department of Biology, Faculty of Sciences of Nature and Life, University of Bechar, Algerian for providing necessary facilities.

\section{REFERENCES}

1. Gurib-Fakim A. Medicinal plants: Traditions of yesterday and drugs of tomorrow. Mol Aspects Med 2006;27(1):1-93.

2. Sira PM. Study of photochemistry and biological activity of Zizyphus mauritiana Lam. (Rhamnceae) used in traditional of diabetes and arterial hypertension Mauritania; 2006, p 33.

3. Kadi H, Moussaoui A, Benmahdi H, Lazouni HA, Benyahia A, Nahar BN. Antibacterial activity of ethanolic and aqueous extracts of Punica granatum L.bark. J Appl Pharm Sci 2011;1(10):180-2.
4. Sarkar M, Tanker M. Phytochemical analysis of Ankara University in the Spring of Eczacicikfaeulte 10.67. Turkey: Ankar; 1991.

5. Wei LS, Musa N, Sengam CT, Schazili WW. Antimicrobial properties of tropical plants against 12 pathogenic bacteria isolated from aquatic organisms. Afr J Biotechnol 2008;7:2275-8.

6. Yasoubi P, Barzegar M, Sahari MA, Azizi MH. Total phenolic contents and antioxidant activity of Pomegranate (Punica granatum L.) peel extracts. J Agric Sci Technol 2007;9:35-42.

7. Pitt JI. An appraisal of identification methods for Penicillium species: Novel taxonomic criteria based on temperature and water relations. Mycology 1973;65:1135-57.

8. Fandohan P, Gbenou JD, Gnonlonfin B, Hell K, Marasas WF, Wingfield MJ. Effect of essential oils on the growth of Fusarium verticillioides and fumonisin contamination in corn. J Agric Food Chem 2004;52(22):6824-9.

9. Hibar K, Daami-Romadi N, Jabnoun-Khiareddine H, Znaidi IE, Elmahjoub M. Effect of ectracts compost at mycelial growth and aggressiveness of Fusarium oxysporum f.sp". rootlycop rsici. Biotechnol Agron Soc Environ 2006;10(2):101-8.

10. Alaa S, Abdellah M, Hamadi L. Phytochemical screening, antifungal and antimycotoxicological effect of Acacia raddiana leaves of SouthWest Algeria. J Chem Pharm Res 2015;7(10):852-6.

11. Nguyen MT. Identification of species of fungal producing of mycotoxins in the riz commercialize in five province of the region of Vietnamstudy of conditions can reducing the production of mycotoxins. These of doctorat, national institute of polythecnic, 2007; Toulouse. France.

12. Muchuweti M, Ndhlala AR, Kasiamhuru A. Analysis of phenolic compounds including tanins, gallotanins and flavanols of Uapaca kirkiana fruit. Food Chem 2006;94(3):415-9.

13. Soumia DZ. Study of biological ativity of ectracts of fruit of Zizyphus lotus. These of Magister. University El-hadj Lakhder Batna; 2006. 